\title{
Low levels of serum miR-99a is a predictor of poor prognosis in breast cancer
}

\author{
J. Li ${ }^{1}$, Z.J. Song' ${ }^{2}$, Y.Y. Wang ${ }^{1}$, Y. Yin ${ }^{1}$, Y. Liu ${ }^{1}$ and X. Nan ${ }^{1}$ \\ ${ }^{1}$ Tumor Research Department, Shaanxi Provincial Tumor Hospital, \\ Xi'an, China \\ ${ }^{2}$ Breast Surgery Center, Shaanxi Provincial Tumor Hospital, Xi'an, China \\ Corresponding author: J. Li \\ E-mail: lijunsxch@163.com
}

Genet. Mol. Res. 15 (3): gmr.15038338

Received December 23, 2015

Accepted April 11, 2016

Published August 26. 2016

DOI http://dx.doi.org/10.4238/gmr.15038338

Copyright $(2016$ The Authors. This is an open-access article distributed under the terms of the Creative Commons Attribution ShareAlike (CC BY-SA) 4.0 License.

\begin{abstract}
MicroRNA (miRNA) deregulation has been previously linked to the initiation and development of breast cancer. Although miR99a is aberrantly expressed in many types of cancers, including breast cancer, the serum miR-99a expression level in breast cancer and its clinical significance remains unknown. Blood samples were obtained from 72 patients with breast cancer and 40 healthy volunteers, and subjected to real-time polymerase chain reaction to evaluate the level of expression of serum miR-99a in the study participants. Furthermore, we investigated the association between serum miR-99a and the clinical outcome of breast cancer. Serum miR-99a expression was significantly downregulated in patients with breast cancer, compared to that in healthy controls $(\mathrm{P}<0.01)$. Moreover, the serum miR-99a was correlated with various clinical parameters of breast cancer, including lymph node metastasis $(\mathrm{P}=0.0194)$, distant metastasis $(\mathrm{P}=0.0037)$, Ki67 intensity $(\mathrm{P}=0.0164)$, TNM stage $(\mathrm{P}=0.0096)$, and histological grade $(\mathrm{P}=$ $0.0051)$ of cancer. Additionally, breast cancer patients displaying lower
\end{abstract}


miR-99a levels showed poorer overall survival rates $(\mathrm{P}=0.0411)$. The serum miR-99a level was also found to be an independent risk factor for breast cancer (hazard ratio $=3.176,95 \%$ confidence interval $=1.543-7.360, \mathrm{P}=0.023$ ). Our data indicated that serum miR-99a expression was downregulated in breast cancer patients; moreover, this downregulation was associated with poor prognosis, suggesting that serum miR-99a could function as a tumor suppressor in breast cancer.

Key words: Breast cancer; miR-99a; Prognosis; Serum

\section{INTRODUCTION}

Breast cancer, the leading cause of cancer-related deaths in women worldwide, is a common and highly lethal malignancy (Jemal et al., 2011). Despite considerable advances in the screening and treatment of breast cancer, its prognosis and long-term survival remain poor for patients in the advanced stages of the disease, especially in cases with metastasis (Soerjomataram et al., 2008). Although some biomarkers such as estrogen receptor (ER) and progesterone receptor (PR) are helpful in the treatment of breast cancer, they are not sensitive and accurate enough to predict the prognosis of breast cancer. Therefore, it is very important to identify biomarkers that can be used to detect breast cancer during the early clinical stages of the disease, as well as predict its prognosis.

MicroRNA (miRNA) are a family of small, non-coding RNA (21-25 nucleotides) that regulate gene expression by inhibiting translation or by directly inducing transcript degradation (He and Hannon, 2004; Wahid et al., 2010). A few reports suggest that miRNA play an essential role in the regulation of cancer initiation and progression (Zhang et al., 2007). miRNA deregulation is a common characteristic of most, if not all, cancer types. miRNA may act as oncogenes or tumor suppressors in tumorigenesis, depending on the cellular context. A number of miRNA are implicated in the carcinogenesis of breast cancer (Blenkiron et al., 2007; Fu et al., 2011). For example, miR-33b expression is downregulated in breast cancer samples, compared to that in normal controls. Furthermore, reduced miR-33b expression has been shown to promote oncogenic behavior in cancer cells and vice versa, indicating that miR$33 \mathrm{~b}$ plays a tumor suppressive role in the development of breast cancer (Lin et al., 2015). On the other hand, Shen et al. (2014) reported a significant increase in the expression of miR-148b and miR-133a in plasma samples obtained from breast cancer patients. Additionally, certain breast cancer cell lines were shown to secrete miR-148b and miR-133a, suggesting the use of these miRNA as potential biomarkers for breast cancer detection (Shen et al., 2014).

Altered expression of miR-99a has been reported in multiple cancer types, including bladder cancer, non-small cell lung cancer, and breast cancer (Sun et al., 2014; Wu et al., 2014; Yu et al., 2015). However, the serum miR-99a expression pattern in patients with breast cancer and its potential clinical significance remains to be elucidated. Therefore, the purpose of this study was to evaluate the clinical value of serum miR-99a levels in breast cancer diagnosis and prognosis.

\section{MATERIAL AND METHODS}

\section{Study participants}

This study was approved by the Ethics Committee of the Shaanxi Provincial Tumor

Genetics and Molecular Research 15 (3): gmr.15038338 
Hospital. Informed consent was obtained from all participants ( 72 breast cancer patients and 40 healthy volunteers). All participants received treatments from, or underwent a physical examination at the Tumor Research Department, Shaanxi Provincial Tumor Hospital. None of the patients received any type of therapy prior to enrolment in this study. No statistically significant difference was detected between the patient and control groups in terms of age. Clinical data of breast patients is summarized in Table 1.

\begin{tabular}{|c|c|c|c|c|}
\hline \multirow[t]{2}{*}{ Variables } & \multirow[t]{2}{*}{$\mathrm{N}$} & \multicolumn{2}{|c|}{ Serum miR-99a expression } & \multirow[t]{2}{*}{$P$} \\
\hline & & Low $(\mathrm{N}=47)$ & High $(\mathrm{N}=25)$ & \\
\hline Age (years) & & & & 0.6294 \\
\hline$<35$ & 15 & 9 & 6 & \\
\hline$\geq 35$ & 57 & 38 & 19 & \\
\hline Menopausal status & & & & 0.5537 \\
\hline Premenopausal & 38 & 26 & 12 & \\
\hline Postmenopausal & 34 & 21 & 13 & \\
\hline Lymph node metastasis & & & & 0.0194 \\
\hline Positive & 21 & 18 & 3 & \\
\hline Negative & 51 & 29 & 22 & \\
\hline Distant metastasis & & & & 0.0037 \\
\hline Positive & 13 & 13 & 0 & \\
\hline Negative & 59 & 34 & 25 & \\
\hline ER status & & & & 0.0801 \\
\hline Positive & 24 & 19 & 5 & \\
\hline Negative & 48 & 28 & 20 & \\
\hline PR status & & & & 0.6386 \\
\hline Positive & 29 & 18 & 11 & \\
\hline Negative & 43 & 29 & 14 & \\
\hline HER-2 status & & & & 0.3543 \\
\hline Positive & 16 & 12 & 4 & \\
\hline Negative & 56 & 35 & 21 & \\
\hline Ki67\% & & & & 0.0164 \\
\hline$<14$ & 35 & 18 & 17 & \\
\hline$\geq 14$ & 37 & 29 & 8 & \\
\hline TNM stage & & & & 0.0096 \\
\hline I-II & 46 & 25 & 21 & \\
\hline III-IV & 26 & 22 & 4 & \\
\hline Histological grade & & & & 0.0051 \\
\hline Well+moderate & 48 & 26 & 22 & \\
\hline Poor & 24 & 21 & 3 & \\
\hline
\end{tabular}

ER, estrogen receptor; PR, progesterone receptor; HER-2, receptor tyrosine-protein kinase erbB-2.

\section{Serum sample collection}

Blood samples $(5 \mathrm{~mL})$ were drawn from the patients and healthy volunteers, collected in tubes without anticoagulant, and allowed to clot at $25^{\circ} \mathrm{C}$ for $30 \mathrm{~min}$. These samples were then centrifuged at $3500 \mathrm{~g}$ for $5 \mathrm{~min}$ at room temperature. The serum was transferred to an RNA-free EP tube, and stored at $-80^{\circ} \mathrm{C}$ until further use.

\section{Real-time PCR}

miRNA was extracted from serum samples $(500 \mu \mathrm{L})$ using the miRcute miRNA Isolation kit (Tiangen Biotech Co., Ltd., Beijing, China) according to the manufacturer instructions. Complementary DNA for miR-99a was obtained by reverse transcription, using a standard kit (Transcriptor First-Strand cDNA Synthesis kit; Roche Diagnostics GmbH, 
Mannheim, Germany). The cDNA strands were amplified using the SYBR ${ }^{\mathrm{TM}}$ Green master mix (Thermo Scientific, Waltham, MA, USA), and the PCR was run on the Thermal Cycler Dice TP800 (Takara Bio Inc., Otsu, Japan). Each experiment was composed of three samples, and was performed in triplicate. The qPCR primers used in this study are summarized in Table 2.

Table 2. Quantitative polymerase chain reaction (qPCR) primers.

\begin{tabular}{l|l}
\hline miR-99a forward & 5'-GGCAAACCCGTAGATCCGA-3' \\
\hline miR-99a reverse & 5'-TCCGTTGGTTGTCCCATAGACT-3' \\
\hline U6 snRNA forward & 5'-TCGCTTCGGCAGCACATATACT-3' \\
\hline U6 snRNA reverse & 5'-ACGCTTCACGAATTTGCGTGTC-3' \\
\hline
\end{tabular}

\section{Statistical analysis}

The obtained data were statistically analyzed using SPSS v.21.0 (IBM, Armonk, NY, USA). Differences with $\mathrm{P}$ values $<0.05$ were considered to be statistically significant. The serum miR-99a level relative to that of U6 snRNA was quantified using the $2^{-\Delta \Delta C t}$ method. The Mann-Whitney test was used to assess the differences in the expression of serum miR99a between the breast cancer patients and healthy volunteers. The correlation between the clinicopathological parameters of the patients and the serum miR-99a expression level was evaluated using the $\chi^{2}$ test, and the association between the serum miR-99a expression and overall survival was estimated by the Kaplan-Meier method. The Cox proportional hazard model was used to identify whether serum miR-99a was an independent risk factor for breast cancer, via a multivariate analysis.

\section{RESULTS}

\section{Serum miR-99a expression levels in breast cancer patients and healthy volunteers}

The real-time PCR results indicated that serum miR-99a expression was significantly downregulated in patients with breast cancer, compared to that in healthy subjects $(\mathrm{P}<0.01$; Figure 1).

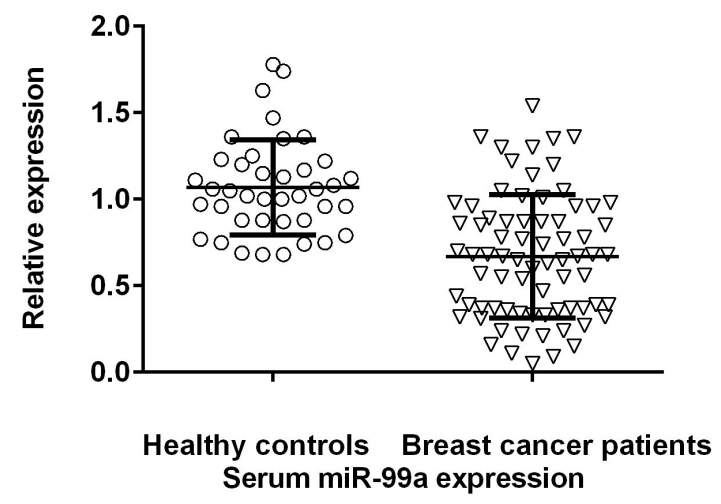

Figure 1. Expression level of serum miR-99a was remarkably reduced in breast cancer patients in comparison with the controls $(\mathrm{P}<0.01)$.

Genetics and Molecular Research 15 (3): gmr.15038338 


\section{Association between serum miR-99a expression and clinical parameters of breast cancer}

The expression level of serum miR-99a was significantly correlated with multiple clinicopathological parameters of breast cancer, including lymph node metastasis $(\mathrm{P}=0.0194)$, distant metastasis $(\mathrm{P}=0.0037)$, Ki67 intensity $(\mathrm{P}=0.0164)$, TNM stage $(\mathrm{P}=0.0096)$, and histological grade $(P=0.0051)$. However, it was not associated with the age $(P=0.6294)$, menopausal status $(\mathrm{P}=0.5537)$, ER status $(\mathrm{P}=0.0801)$, $\mathrm{PR}$ status $(\mathrm{P}=0.6386)$, and HER2 status $(\mathrm{P}=0.3543)$ of the breast cancer patients (Table 1$)$.

\section{Association between serum miR-99a expression and overall survival}

The 5-year overall survival rate of breast cancer patients with low serum miR-99a expression was $55.32 \%$, which was significantly lower than that shown by patients with a higher serum miR-99a content $(80.00 \%$ overall survival rate; $\mathrm{P}=0.0411)$ (Figure 2$)$.

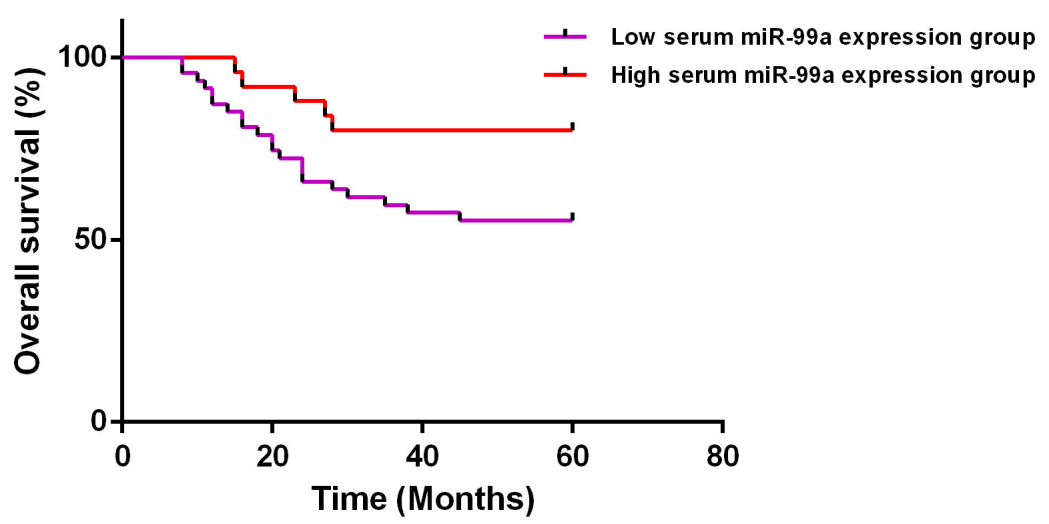

Figure 2. Breast cancer patients with lower serum miR-99a suffered a poorer 5-year overall survival rate $(\mathrm{P}=$ $0.0411)$.

\section{Serum miR-99a is an independent prognostic factor for breast cancer}

Multivariate analyses showed that distant metastasis $(\mathrm{HR}=3.620,95 \% \mathrm{CI}=1.545$ 9.364, $\mathrm{P}=0.012)$, TNM stage ( $\mathrm{HR}=4.015,95 \% \mathrm{CI}=1.784-12.068, \mathrm{P}=0.009)$, histological grade $(\mathrm{HR}=3.382,95 \% \mathrm{CI}=1.679-8.151, \mathrm{P}=0.017)$, and low serum miR-99a expression level $(\mathrm{HR}=3.176,95 \% \mathrm{CI}=1.543-7.360, \mathrm{P}=0.023)$ were independent risk factors for breast cancer (Table 3).

Table 3. Multivariate analyses of different prognostic parameters for breast cancer.

\begin{tabular}{l|c|c|c}
\hline \multirow{2}{*}{ Variables } & \multicolumn{3}{|c}{ Overall survival } \\
\cline { 2 - 4 } & HR & $95 \%$ CI & P \\
\hline Distant metastasis (positive $v s$ negative) & 3.620 & $1.545-9.364$ & 0.012 \\
\hline TNM stage (III-IV $v s$ I-II) & 4.015 & $1.784-12.068$ & 0.009 \\
\hline Histological grade (poor $v s$ well+moderate) & 3.382 & $1.679-8.151$ & 0.017 \\
\hline Serum miR-99a expression level (low $v s$ high) & 3.176 & $1.543-7.360$ & 0.023 \\
\hline
\end{tabular}

HR, hazard ratio; CI, confidence interval. 


\section{DISCUSSION}

Detecting breast cancer at an early clinical stage is essential for disease control. Patients with breast cancer can significantly benefit from early diagnosis and treatment, which would improve the prognosis and long-term survival of this malignancy. Therefore, it is important and crucial to explore for biomarkers for early cancer diagnosis and prognosis. In this study, our results showed that the expression of miR-99a was significantly downregulated in serum samples from breast cancer patients, in comparison with that seen in healthy controls. Low serum miR-99a expression was also associated with several important clinicopathological parameters of breast cancer, including lymph node metastasis, distant metastasis, Ki67 intensity, TNM stage, and histological grade. Moreover, breast cancer patients displaying lower levels of miR-99a also showed poorer overall survival rates. The multivariate analysis also revealed low serum miR-99a levels to be an independent risk factor for breast cancer. Based on these findings, miR-99a was believed to play a tumor suppressive role in breast cancer; in fact, loss of miR-99a was shown to promote the development of this malignancy.

Sun et al. (2014) observed that the miR-99a expression was downregulated in ductal carcinoma in the breast, using an miRNA microarray, which was consistent with our results. Similarly, Wang et al. (2015) reported that breast cancer tissues showed downregulated miR99a expression compared to the normal tissues, which was highly correlated with lymph node metastasis and shorter overall survival. Moreover, ectopic expression of miR-99a was shown to inhibit the proliferation, migration, and invasion of breast cancer cells in vitro and vice versa, which indicated that miR-99 functioned as a tumor suppressor in breast cancer (Wang et al., 2015). Yang et al. (2014) reported a decrease in miR-99a in a side population (SP) of cancer cells, compared to non-SP cancer cells. miR-99a overexpression inhibited the oncogenic behavior of SP cancer cells by targeting the mTOR signaling pathway, suggesting that the miR-99a expression was closely associated with the breast cancer malignant stem cell phenotype. Similarly, Hu et al. (2014) observed a decrease in the miR-99a expression level in breast cancer tissue specimens as well as cell lines. The anti-cancer property of miR-99a was mediated by inhibiting the mTOR/p-4E-BP1/p-S6K1 pathway (Hu et al., 2014).

miR-99a also has an anti-tumor effect on multiple types of cancer other than breast cancer. Oral cancer cell lines and clinical specimens showed reduced expression of miR-99a. Additionally, reinforced expression of miR-99a suppressed the migration and invasion of oral cancer cells by inhibiting myotubularin-related protein 3 expression, indicating miR-99a as a tumor suppressor in oral cancer (Kuo et al., 2014). Gu et al. (2013) reported that the miR-99a expression was significantly lower in lung adenocarcinoma cells than that in normal lung bronchial epithelial cells. Moreover, miR-99a was shown to inhibit growth and induce apoptosis by targeting the mTOR pathway, and low miR-99a expression was associated with poor clinical outcome (Gu et al., 2013). Similarly, Li et al. (2011) observed a decrease in the expression of miR-99a in hepatocellular carcinoma (HCC) tissues, correlated with the prognosis of HCC patients. miR-99a was also demonstrated to be an independent prognosis predictor of HCC. In vitro experimentation revealed that miR-99a inhibits the proliferation of HCC cells by inducing cell cycle arrest, suggesting miR-99a to be a potential tumor suppressor of $\mathrm{HCC}$ (Li et al., 2011).

Some miRNA may function as oncogenes or tumor suppressors, depending on the downstream targets. Although miR-99a acts as a tumor suppressor in most types of cancers investigated so far, it may also play an oncogenic role in cancer progression. miR-99a

Genetics and Molecular Research 15 (3): gmr.15038338 
expression was significantly upregulated in patients with pediatric acute myeloid leukemia/ chronic myeloid leukemia, and downregulated in patients who achieved complete remission. This indicated that miR-99a might be a promising marker for monitoring therapeutic responses. In addition, miR-99a was shown to promote proliferation and inhibit apoptosis in leukemia cell lines (Zhang et al., 2013). Therefore, the exact role of miR-99a in tumorigenesis might depend on the specific cancer type.

\section{CONCLUSIONS}

Taken together, our data indicated that decreased expression of serum miR-99a was associated with poor prognosis of breast cancer. Thus, serum miR-99a may serve as a prognostic marker for breast cancer.

\section{Conflicts of interest}

The authors declare no conflict of interest.

\section{ACKNOWLEDGMENTS}

We acknowledge Dr. Xu for editing support and Dr. Zeng for technical support.

\section{REFERENCES}

Blenkiron C, Goldstein LD, Thorne NP, Spiteri I, et al. (2007). MicroRNA expression profiling of human breast cancer identifies new markers of tumor subtype. Genome Biol. 8: R214. http://dx.doi.org/10.1186/gb-2007-8-10-r214

Fu SW, Chen L and Man YG (2011). miRNA biomarkers in breast cancer detection and management. J. Cancer 2: 116122. http://dx.doi.org/10.7150/jca.2.116

Gu W, Fang S, Gao L, Tan Y, et al. (2013). Clinic significance of microRNA-99a expression in human lung adenocarcinoma. J. Surg. Oncol. 108: 248-255. http://dx.doi.org/10.1002/jso.23381

Jemal A, Bray F, Center MM, Ferlay J, et al. (2011). Global cancer statistics. CA Cancer J. Clin. 61: 69-90. http://dx.doi. org/10.3322/caac. 20107

He L and Hannon GJ (2004). MicroRNAs: small RNAs with a big role in gene regulation. Nat. Rev. Genet. 5: 522-531. http://dx.doi.org/10.1038/nrg1379

Hu Y, Zhu Q and Tang L (2014). MiR-99a antitumor activity in human breast cancer cells through targeting of mTOR expression. PLoS One 9: e92099. http://dx.doi.org/10.1371/journal.pone.0092099

Kuo YZ, Tai YH, Lo HI, Chen YL, et al. (2014). MiR-99a exerts anti-metastasis through inhibiting myotubularin-related protein 3 expression in oral cancer. Oral Dis. 20: e65-e75. http://dx.doi.org/10.1111/odi.12133

Li D, Liu X, Lin L, Hou J, et al. (2011). MicroRNA-99a inhibits hepatocellular carcinoma growth and correlates with prognosis of patients with hepatocellular carcinoma. J. Biol. Chem. 286: 36677-36685. http://dx.doi.org/10.1074/ jbc.M111.270561

Lin Y, Liu AY, Fan C, Zheng H, et al. (2015). MicroRNA-33b inhibits breast cancer metastasis by targeting HMGA2, SALL4 and Twist1. Sci. Rep. 5: 9995. http://dx.doi.org/10.1038/srep09995

Shen J, Hu Q, Schrauder M, Yan L, et al. (2014). Circulating miR-148b and miR-133a as biomarkers for breast cancer detection. Oncotarget 5: 5284-5294. http://dx.doi.org/10.18632/oncotarget.2014

Soerjomataram I, Louwman MW, Ribot JG, Roukema JA, et al. (2008). An overview of prognostic factors for long-term survivors of breast cancer. Breast Cancer Res. Treat. 107: 309-330. http://dx.doi.org/10.1007/s10549-007-9556-1

Sun EH, Zhou Q, Liu KS, Wei W, et al. (2014). Screening miRNAs related to different subtypes of breast cancer with miRNAs microarray. Eur. Rev. Med. Pharmacol. Sci. 18: 2783-2788.

Wahid F, Shehzad A, Khan T and Kim YY (2010). MicroRNAs: synthesis, mechanism, function, and recent clinical trials. Biochim. Biophys. Acta 1803: 1231-1243. http://dx.doi.org/10.1016/j.bbamcr.2010.06.013

Genetics and Molecular Research 15 (3): gmr.15038338 
Wang X, Li Y, Qi W, Zhang N, et al. (2015). MicroRNA-99a inhibits tumor aggressive phenotypes through regulating HOXA1 in breast cancer cells. Oncotarget 6: 32737-32747.

Wu D, Zhou Y, Pan H, Zhou J, et al. (2014). microRNA-99a inhibiting cell proliferation, migration and invasion by targeting fibroblast growth factor receptor 3 in bladder cancer. Oncol. Lett. 7: 1219-1224.

Yang Z, Han Y, Cheng K, Zhang G, et al. (2014). miR-99a directly targets the mTOR signalling pathway in breast cancer side population cells. Cell Prolif. 47: 587-595. http://dx.doi.org/10.1111/cpr.12146

Yu SH, Zhang CL, Dong FS and Zhang YM (2015). miR-99a suppresses the metastasis of human non-small cell lung cancer cells by targeting AKT1 signaling pathway. J. Cell. Biochem. 116: 268-276. http://dx.doi.org/10.1002/ jcb. 24965

Zhang B, Pan X, Cobb GP and Anderson TA (2007). microRNAs as oncogenes and tumor suppressors. Dev. Biol. 302: 1-12. http://dx.doi.org/10.1016/j.ydbio.2006.08.028

Zhang L, Li X, Ke Z, Huang L, et al. (2013). MiR-99a may serve as a potential oncogene in pediatric myeloid leukemia. Cancer Cell Int. 13: 110. http://dx.doi.org/10.1186/1475-2867-13-110

Genetics and Molecular Research 15 (3): gmr.15038338 